\title{
Analysis of yield stability of strawberry varieties and hybrids
}

\author{
Vadim Lapshin ${ }^{1 *}$, Valentina Yakovenko ${ }^{1}$, and Sergey Shcheglov ${ }^{2}$ \\ ${ }^{1}$ Federal State Budget Scientific Institution «North Caucasian Federal Scientific Center of Horticul- \\ ture, Viticulture, Wine-making», 350901, 39 str. 40 Let Pobedy, Krasnodar, 350901, Russia \\ ${ }^{2}$ Federal State Budgetary Educational Institution of Higher Education «Kuban State University», \\ Stavropolskaya street, 149, Krasnodar, Russian Federation
}

\begin{abstract}
The profitability of strawberry cultivation is largely determined by the capacity and quality of the yield, depended on the features of the variety genotype. The aim of this work was to estimate the yield stability of varieties and hybrids by the methods of multivariate statistical analysis and identify the best genotypes. To solve this problem, we have used the twofactor analysis of variance and hierarchical cluster analysis according to the Ward's method as well as the integral estimate of the differences between the values of yield. The results of the studies have shown that the genotype of the variety (hybrid) are makes a decisive factor of influence for variability of the yield structure signs from $17,1 \%$ (number of inflorescences) to $32,2 \%$ (number of berries). The «genotype $\times$ environment» interaction is comparable with the genotype influence, the share of influence of the year conditions of the year is insignificant. Cluster analysis according to complex of economic valuable signs allows us to identify the eight forms that the most adapted to the conditions of the Krasnodar Territory as 13-1-15, Florence, Roxana, 18-1-15, Asia, Onda, Kemia, Nelli from which the Roxana, Florence, 18-1-15, 13-1-15 have a high and steadily rising biological yield.
\end{abstract}

\section{Introduction}

Today the Garden strawberry (Fragaria $\times$ ananassa Duch.) is leading cultivated and consumed berry crop in the world. The production of strawberry in the world is constantly rising due to an increase in variety diversity and improvement of cultivation technologies and this production recently is about 9,2 million tons [1].

The profitability of strawberry production depends on many factors, the key ones from them are the genotype of the variety and the growing conditions, so the right variety selection well adapted to the environmental conditions of the place of growth is an important feature for its successful cultivation [2-4].

An influence of environmental conditions, according to J. Paderewski and W. Mądry [5], the specifics of traits manifestation in individual genotypes is complicated and difficult to interpret and manifests itself in a different reaction of quantitative indicators of strawber-

\footnotetext{
*Corresponding author: lavai@list.ru
} 
ry genotypes to growing conditions, another words, in the «genotype $\times$ environment» interaction.

The most for industry and breeding are genotypes with a steady high yield, that is with the yield that has relatively low variability according to the interaction of «genotype $\times$ environment».

There are a number of works are dedicated to assessment of the «genotype $\times$ environment» interaction and the identification of the most stable in terms of yield and quality of berries varieties and hybrid forms of strawberry in the specific growing conditions [6-8]. The basis of the analysis of the variability of the strawberry economic and biological characteristics in these studies is multivariate statistical methods that are allow to study the objects on the complex of traits.

Using the methods of mathematical statistics, it is possible to analyze the main direction of genotypes variability and thus to distinguish the reactions of the studied forms to changes in the environment conditions of the growing environment [9-10].

Every year, an essential number of new varieties and hybrids of strawberry are supplied to the world and domestic markets, the biological potential of which is insufficiently studied, therefore, the works on the estimation of genotypic stability which is determined by the norm of these genotypes reaction to specific growing conditions is still relevant today [1113].

The aim of this work was to estimate the yield stability of strawberry varieties and hybrids based on the using the methods of multivariate statistical analysis and to identify the best genotypes.

\section{Objects and methods of research}

In the work 11 varieties and 7 hybrids of strawberry from the collection of the FSBSI NCFSCHVW was studied: these are Nelli, Kemia, Taira, Alba, Syria, Asia, Roxana, Florence, Onda, Clery, Belrubi, 5-5-08, 2-14-08, 5 3-12, 5-1-12, 2-5-12, 18-1-15, 13-1-15.

Genotypes were evaluated in 2016-2019. The yield and the traits of the yield structure were analyzed: biological yield, number of inflorescences, flowers, berries and average fruit weight.

For the assess of the variability of traits studied, the analysis of variance was used. To create of homogeneous groups, the hierarchical cluster analysis by the Ward's method was used and Euclidean distances were calculated. To illustrate the multivariate similarity of the strawberry genotypes studied, a diagram of their distribution in two-dimensional space was made.

The traits study was carried out according to the generally accepted in the Russian Federation the special guide as Program and methodology of variety study of fruit, berry and nut-bearing crops. For statistical data treatment, a number of specialized methods [14-15] and the Statistica v.10 software package was used.

\section{Results and discussion}

The first step of the research was assessing the influence of the strawberry genotype, the conditions of the year and their combined affect the economically valuable traits with using by analysis of variance (Table 1). 
Table 1. Analysis of variance of the traits of strawberry productivity and yield

\begin{tabular}{|c|c|c|c|c|c|}
\hline $\begin{array}{l}\text { Variability } \\
\text { factor }\end{array}$ & df & $\mathrm{mS}$ & F & $\sigma^{2}$ & $\begin{array}{l}\text { Proportion in } \\
\text { total } \\
\text { variance }(\%)\end{array}$ \\
\hline \multicolumn{6}{|c|}{ Number of inflorescences } \\
\hline Genotype & 17 & 127,70 & $11,8^{* *}$ & 2,92 & 17,1 \\
\hline Year & 3 & 217,40 & $20,1 * *$ & 1,15 & 6,7 \\
\hline $\begin{array}{c}\text { «Genotype } \times \\
\text { Year» }\end{array}$ & 51 & 32,70 & $3,0 * *$ & 2,19 & 12,8 \\
\hline Residual & 648 & 10,80 & - & 10,80 & 63,3 \\
\hline \multicolumn{6}{|c|}{ Number of flowers } \\
\hline Genotype & 17 & 8103,81 & $24,4 * *$ & 194,30 & 25,6 \\
\hline Year & 3 & 10499,13 & $31,6^{* *}$ & 56,47 & 7,4 \\
\hline $\begin{array}{c}\text { «Genotype } \times \\
\text { Year» }\end{array}$ & 51 & 2086,45 & $6,3 * *$ & 175,45 & 23,1 \\
\hline Residual & 648 & 332,00 & - & 332,00 & 43,8 \\
\hline \multicolumn{6}{|c|}{ Number of berries } \\
\hline Genotype & 17 & 7453,40 & $31,2 * *$ & 180,36 & 32,2 \\
\hline Year & 3 & 4800,95 & $20,1 * *$ & 25,35 & 4,5 \\
\hline $\begin{array}{c}\text { «Genotype } \times \\
\text { Year» }\end{array}$ & 51 & 1386,91 & $5,8^{* *}$ & 114,81 & 20,5 \\
\hline Residual & 648 & 238,84 & - & 238,84 & 42,7 \\
\hline \multicolumn{6}{|c|}{ Fruit weight } \\
\hline Genotype & 17 & 129,84 & $29,9 * *$ & 3,14 & 28,4 \\
\hline Year & 3 & 186,47 & $42,9 * *$ & 1,01 & 9,2 \\
\hline $\begin{array}{c}\text { «Genotype } \times \\
\text { Year» }\end{array}$ & 51 & 27,89 & $6,9^{* *}$ & 2,56 & 23,1 \\
\hline Residual & 648 & 4,34 & - & 4,34 & 39,3 \\
\hline \multicolumn{6}{|c|}{ Biological yield } \\
\hline Genotype & 17 & 2175329,32 & $34,8 * *$ & 52820,41 & 32,4 \\
\hline Year & 3 & 2407613,52 & $38,5 * *$ & 13028,34 & 8,0 \\
\hline $\begin{array}{c}\text { «Genotype } \times \\
\text { Year» }\end{array}$ & 51 & 411241,20 & $6,5 * *$ & 34872,85 & 21,4 \\
\hline Residual & 648 & 62512,89 & - & 62512,89 & 38,3 \\
\hline
\end{tabular}

\footnotetext{
** - differences in factor of variability are significant for a $1 \%$ significance level with standard values of the F-criterion for the factor «genotype» is 1,95 ; factor «year» is 3,78 ; interaction «genotype $\times$ year» is 1,52 .
}

The analysis carried out is shown that the all factors studied, affect the economically valuable traits. The genotype of variety (and hybrid) has the greatest influence over studied traits which is from 17,1 (number of inflorescences) to $32,2 \%$ (number of berries). The influence of «the year of research» was significantly less, from 4,5 (number of berries) to $9,2 \%$ (average fruit weight). The combined influence of the genotype and the year conditions quantitatively corresponds to the influence of the genotype, from 12,8 (number of inflorescences) to $23,1 \%$ (average fruit weight). Thus, the presence of variability among the studied varieties and hybrids was established, as well as their ecological plasticity, expressed as a minimal contribution to the total variability of the conditions of the year of research, was also shown. The genotype-environment interaction has a much greater influ- 
ence over the traits than the influence of the environment all conditions (that is influence of the year of research).

The detected variability of varieties and hybrids allows us to carry out the procedure for selecting of the most promising samples. Traditional statistical methods, as a rule, make it possible to identify simply noted connections between variables of a straight nature. Since we are studing the characteristics of objects on the 5 variables, it is possible to assume that there are complex configurations of relationships between them that could be the result of latent variables.

For the grouping of varieties and hybrids according to a complex of economically valuable traits, we have used a cluster analysis, a method that allows us to divide the set of studied objects into homogeneous groups (clusters). For clustering, the Ward algorithm was used, which forms the groups according to the principle of the superiority of dispersion between clusters over dispersion within clusters. As a result of this agglomerative procedure, the dendrogram is formed (fig. 1).

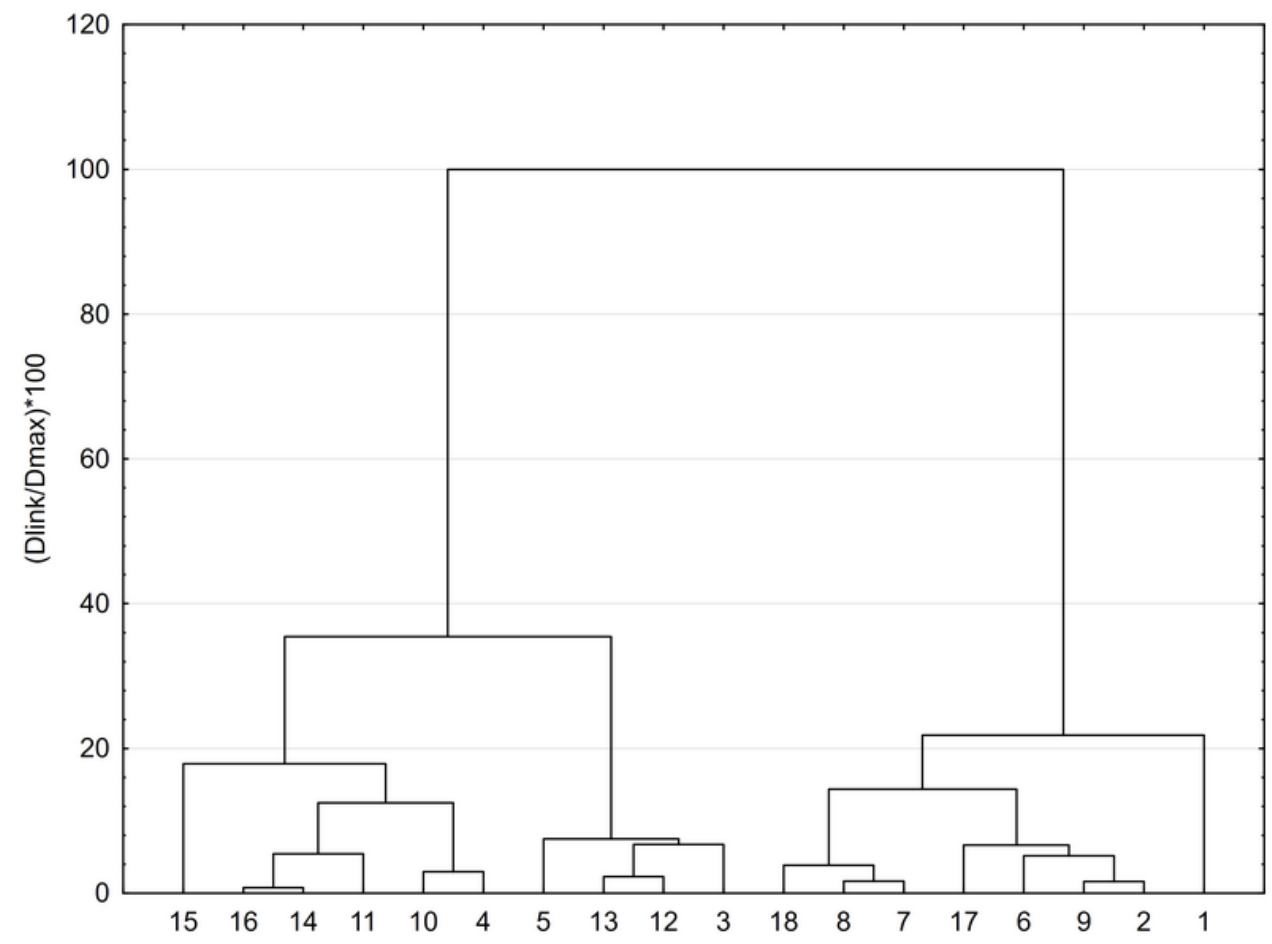

Fig. 1. Results of cluster analysis of strawberry varieties and hybrids

1 - Nelli, 2 - Kemia, 3 - Taira, 4 - NF 311 (Alba), 5 - Syria, 6 - NF 421 (Asia), 7 - NF 205 (Roxana), 8 - Florence, 9 - Onda, 10 - Clery, 11 - Belrubi, 12 - 5-5-08, 13 - 2-14-08, $14-5-3-12,15-5-1-12,16-2-5-12,17-18-1-15,18-13-1-15$.

According to the results of clustering with a fusion coefficient of 25 srvc. units three groups of varieties and hybrids are selected.

In the first group is gathered are 5-1-12 (15), 2-5-12 (16), 5-3-12 (14), Belrubi (11), Clery (10), Alba (4), in the second group - Syria (5), 2-14-08 (13), 5-5-08 (12), Taira (3), in the third group - 13-1-15 (18), Florence (8), Roxana (7), 18-1-15 (17), Asia (6), Onda (9), Kemia (2), Nelli (1). The reliable of the cluster solution was verified with using the variance analysis which was conducted with the «cluster» factor (Table 2). 
Table 2. The results of the variance analysis for economically valuable traits in the groups formed of strawberry varieties and hybrids

\begin{tabular}{|c|c|c|c|c|c|}
\hline Variability & df & $\mathrm{mS}$ & $\mathrm{F}$ & $\sigma^{2}$ & $\begin{array}{c}\text { Proportion in } \\
\text { total } \\
\text { variance (\%) }\end{array}$ \\
\hline \multicolumn{7}{|c|}{ Number of inflorescences } \\
\hline Cluster & 2 & 8,30 & 3,2 & 0,97 & 27,8 \\
\hline Residual & 15 & 2,51 & - & 2,51 & 72,2 \\
\hline \multicolumn{7}{|c|}{ Number of flowers } \\
\hline Cluster & 2 & 809,10 & $6,6^{*}$ & 114,56 & 48,5 \\
\hline Residual & 15 & 121,73 & - & 121,73 & 51,5 \\
\hline \multicolumn{7}{|c|}{ Number of berries } \\
\hline Cluster & 2 & 1233,40 & $26,4^{*}$ & 197,28 & 80,9 \\
\hline Residual & 15 & 46,73 & - & 46,73 & 19,1 \\
\hline \multicolumn{7}{|c|}{ Fruit weight } \\
\hline Cluster & 2 & 9,10 & $3,7^{*}$ & 1,11 & 31,0 \\
\hline Residual & 15 & 2,46 & - & 2,46 & 69,0 \\
\hline \multicolumn{6}{|c|}{ Biological yield } \\
\hline Cluster & 2 & 375341,40 & $32,4^{*}$ & 60625,43 & 84,0 \\
\hline Residual & 15 & 11588,85 & - & 11588,85 & 16,0 \\
\hline
\end{tabular}

* - differences for clusters are significant on the $5 \%$ significance level with a standard $\mathrm{F}$ is 3,68 .

The clusters allocated is statistically significantly differ in all traits, except for the number of inflorescences.

The data in a table 2 indicate the difference in the clusters, but don't show their possible similarities. With the average values of the studied traits in the clusters presented in the Table 3, the intercomparison procedure was carried out using the Student's t-test.

Table 3. Average values of strawberry traits in the resulting clusters

\begin{tabular}{|c|c|c|c|}
\hline Trait & First cluster & Second cluster & Third cluster \\
\hline $\begin{array}{c}\text { Number of inflores- } \\
\text { cences }\end{array}$ & 12,85 & 13,31 & 14,94 \\
\hline Number of flowers & 62,06 & 77,77 & 83,54 \\
\hline Number of berries & 41,71 & 60,53 & 68,31 \\
\hline Fruit weight & 12,55 & 12,62 & 14,61 \\
\hline Biological yield & 533,43 & 769,85 & 1000,45 \\
\hline
\end{tabular}

It has been established that strawberry cultivars and hybrids from the third cluster are characterized by maximal values of traits. When comparing the average values between the first and second clusters with using a Student's t-test, the differences in the number of berries $(\mathrm{t}=5,81$ at $\mathrm{p}<0,05)$ and biological yield $(\mathrm{t}=3,73$ at $\mathrm{p}<0,05)$ are proved. When comparing the second and third clusters, the differences in the average fruit weight $(t=2,76$ at $\mathrm{p}<0,05)$ and biological yield $(\mathrm{t}=3,68$ at $\mathrm{p}<0,05)$ were recognized as reliable. The largest number of differing traits was found between the first (with minimal values) and third (with maximal values) clusters: on the number of inflorescences $(t=2,73$ at $p<0,05)$, the number 
of flowers ( $\mathrm{t}=3,45$ at $\mathrm{p}<0,05)$, the number of berries $(\mathrm{t}=6,53$ at $\mathrm{p}<0,05)$, the average fruit weight $(\mathrm{t}=2,27$ at $\mathrm{p}<0,05)$ and the biological yield $(\mathrm{t}=7,35$ at $\mathrm{p}<0,05)$.

Thus, a cluster analysis made it possible to identify among the 18 strawberry varieties and hybrids 8 ones the most adapted to the conditions of the Krasnodar Territory - 13-1-15, Florence, Roxana, 18-1-15, Asia, Onda, Kemia, Nelli.

An alternative way to identify the promising varieties and hybrids can be the use of the so-called «ideal object», that means a hypothetical variety or hybrid with maximum values of traits from the genetic collection studied. For this it is necessary to calculate the Euclidean distance (metric, which is the geometric distance in multivariate space) from the "ideal object" to each variety or each hybrid, the value of which is determined by the shortest distance to it.

For convenience, the results of calculating the Euclidean distance are presented in order of distance from the «ideal object»: Nelli $(3,321), 18-1-15(180,009)$, Kemia $(264,976)$, Onda (267,360), Asia $(318,614)$, Florence $(325,653)$, Roxana $(356,375)$, 13-1-15 $(357,001)$, Taira $(433,268)$, Syria $(467,491), 2-14-08(521,066), 5-5-08(543,562)$, Alba $(587,588)$, Clery ( 635,913), Belrubi $(677,664), 5-3-12$ (738,754), 2-5-12 (747,196), 5-1-12 $(929,587)$. This method made it possible to range the varieties and hybrids according with their distance from the «ideal object», thereby clarifying the results of varieties and hybrids distribution in a cluster analysis. It should be noted that the structure of the third cluster with the most promising genotypes was coincided completely with the varieties and hybrids located at the shortest distance to the «ideal object» (from Nelli to 13-1-15).

Multidimensional methods, allowed us to select the most promising varieties and hybrids, can be addition completed with traditional statistical methods. We propose an approach, in which the results of cluster analysis and using of the «ideal object» are completed by assessing the stability of fruiting in strawberry genotypes. We carried out the integrating assessment of yield stability, which components were the difference in the yield of varieties and hybrids as comparison of the yield of 2016 and 2017, 2017 and 2018, 2018 and 2019, as well as the coefficient of variation. It is noted that the obtained yield differences are differ not only in value, but also in sign (minus or plus) between two consecutive years of accounting, that allows us to distinguish within the group of studied strawberry genotypes the varieties and hybrids with a qualitatively different reaction to variability of year conditions. In the process of the biological yield analysis the 5 types of yield dynamics are revealed, in which it is shown an increasing $(+)$ or decreasing $(-)$ in biological yield in the following one after another years of fruiting: --+ Kemia, Taira, Alba; $-+-5-3-12,5-$ 1-12; - + + Syria, Belrubi, 5-5-08, 2-14-08, 2-5-12; + - + Nelli, Asia, Roxana, Florence, Onda, Clery; ++ + 19-1-15, 13-1-15.

So, the option marked as «-- +» means that the yield of 2017 yield is decreased in relation to yield of 2016, the yield of 2018 is decreased than that in 2017, and the yield of 2019 is increased in comparison with the yield of 2018. The «+++» option means a steady increase in the berries yield in the years, which were compared.

We propose to use such indicators as the coefficient of variation, characterized the variability or stability of the yield, and the sum of the differences in yield for every year (in our case, we summarize the yield difference in 2017 and 2016; 2018 and 2017; 2019 and 2018). According to the selected specified parameters, a two-dimensional graph was built (Fig. 2). 


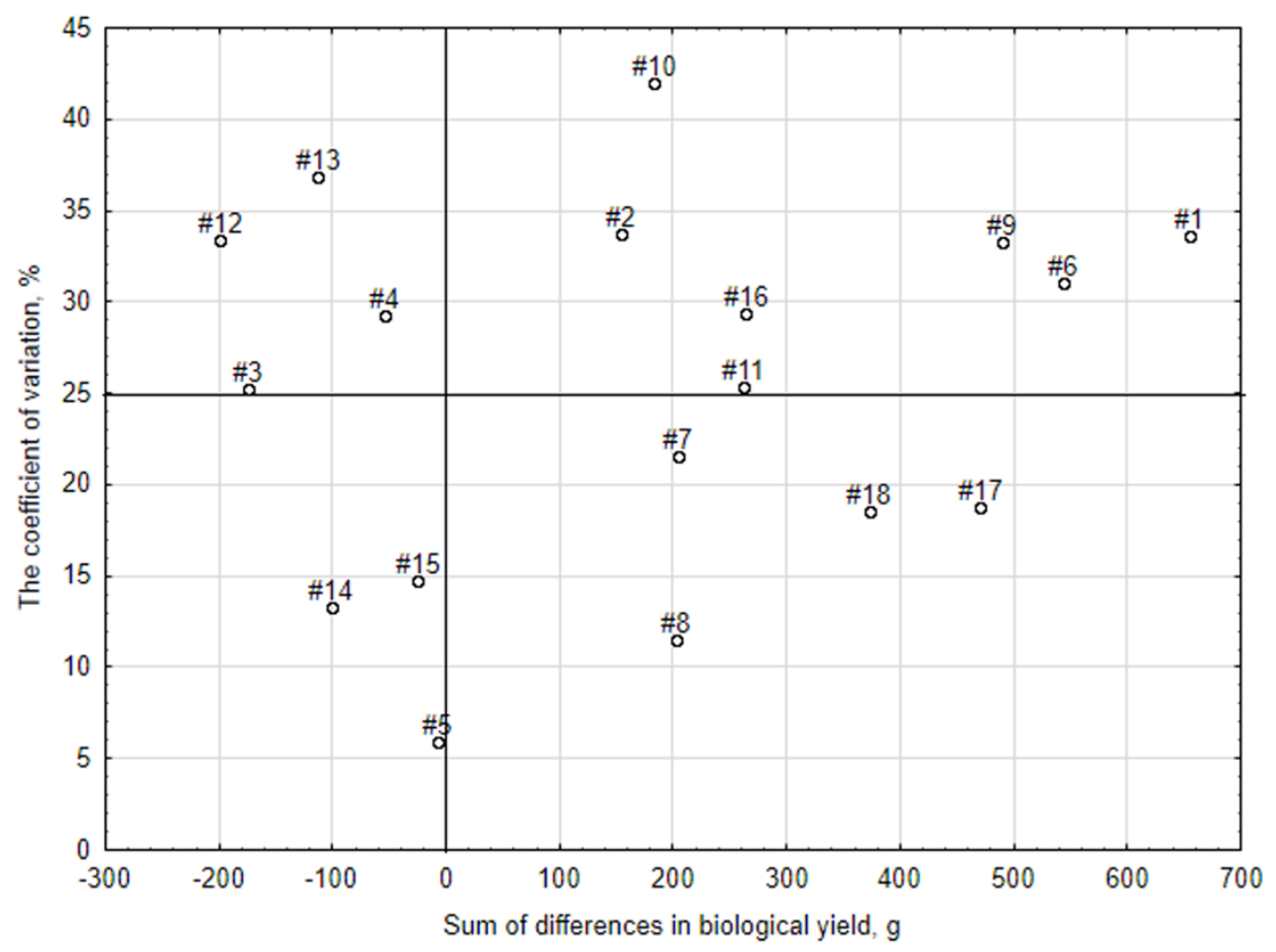

Fig. 2. The distribution of strawberry varieties and hybrids according to yield

1 - Nelli, 2 - Kemia, 3 - Taira, 4 - NF 311 (Alba), 5 - Syria, 6 - NF 421 (Asia), 7 - NF 205 (Roxana), 8 - Florence, 9 - Onda, 10 - Clery, 11 - Belrubi, 12 - 5-5-08, 13 - 2-14-08, $14-5-3-12,15-5-1-12,16-2-5-12,17-18-1-15,18-13-1-15$.

To separate the varieties and hybrids, the average value of the coefficient of variation for the whole population was used (it was equal to $25 \%$ ) as well as the values of the sum of the differences in the yield exceeded zero values. After drawing the perpendicular lines on the graph, the four quadrants were obtained. Varieties with a stable low yield increasing were included in the left quadrant of low part of the graph, with the varieties unstably low yield increasing are in the upper left quadrant, ones with an unstably high yield increase are in the upper right quadrant, and stable high yield increase the varieties with are in the right quadrant of four part.

As a result of the analysis of figure 2, the varieties and hybrids under study were divided into 4 groups:

1) with a stable low yield increasing: Syria (5), 5-3-12 (14), 5-1-12 (15);

2) with an unstable low yield increasing: Taira (3), Alba (4), 5-5-08 (12), 2-14-08 (13);

$3)$ with an unstable high yield increasing: Clery (10), Kemia (2), 2-5-12 (16), Belrubi (11), Onda (9), Asia (6), Nelli (1);

4) with a stable high yield increasing: Roxana (7), Florence (8), 18-1-15 (17), 13-1-15 (18). 
It was established that among of 8 promising strawberry varieties and hybrids selected with using of statistical methods the varieties of Roxana, Florence, 18-1-15, 13-1-15, not only high, but also stable increasing in the biological yield. The Kemia and Nelli, varieties of local breeding, also have a good production prospects due to the positive dynamics of yield increasing.

\section{References}

1. E. Barth, J. T. V. de Resende, A. F. P. Moreira, K. H. Mariguele, A. R. Zeist, M. B. Silva, G. C. G. Stulzer, J. G. M. Mafra, L. S. A. Gonçalves, S. R. Roberto, K. Youssef, Agron. 10, $598 \quad$ (2020). DOI: 10.3390/agronomy10040598, URL: https://www.mdpi.com/2073-4395/10/4/598/pdf

2. Fontana, C. Cocco, M. I. Diel, M. M. Pretto, E. Holz, A. Werner, V. Testa, B. O. Caron, J. Stolzle, M. V. M. Pinheiro, D. Schmidt, Int. J. Curr. Res. 8 (07), 33889-33893 (2016). URL: https://www.journalcra.com/sites/default/files/issue-pdf/15877.pdf

3. Neetu, S. P. Sharma, Int. J. Curr. Microbiol. App. Sci. 7 (02), 2835-2840 (2018). DOI: $\quad 10.20546 /$ ijcmas.2018.702.345, URL: https://www.ijcmas.com/7-22018/Neetu\%20and\%20Shishir\%20Prakash\%20Sharma.pdf

4. D. S. Zanin, A. F. Fagherazzi, A. M. dos Santos, R. Martins, A. A. Kretzschmar, L. Rufato, Rev. Ceres. Viçosa 66 (3), 159-167 (2019). DOI: 10.1590/0034737x201966030001, URL: https://www.scielo.br/pdf/rceres/v66n3/0034-737X-rceres-6603-159.pdf

5. J. Paderewski, W. Mądry, Biuletyn IHAR NR 263, 161-188 (2012). URL: biblioteka.ihar.edu.pl/show_pdf.php?src=pdf/05/1d3e77be.pdf\&name=JAKUB\%20PADE REWSKI,\%20WIES\%A3AW\%20M\%A1DRY.pdf

6. M. Höfer, R. Drewes-Alwarez, P. Scheewe, K. Olbricht, J. Berry Res. 2, 191-206 (2012). DOI: 10.3233/JBR-2012-042, URL: https://pdfs.semanticscholar.org/e776/ 2c922d37ca1f9d030902a8718379ea2d5cb9.pdf

7. L. Sieczko, A. Masny, K. Pruski, E. Żurawicz, W. Mądry, Hort. Sci. 42 (2), 83-93 (2015). DOI: 10.17221/123/2014-HORTSCI, URL: https://www.agriculturejournals.cz/ publicFiles/123_2014-HORTSCI.pdf

8. E. Krüger, M. Josuttis, R. Nestby, T. B. Toldam-Andersen, C. Carlen, B. Mezzetti,

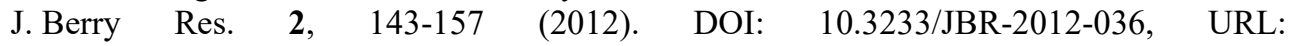
https://content.iospress.com/download/journal-of-berry-research/jbr036?id=journal-ofberry-research $\% 2 \mathrm{Fjbr} 036$

9. C. Achir, P. Annicchiarico, L. Pecetti, H.-E. Khelifi, M. M'Hammedi-Bouzina, A. Abdelguerfi, M. Laouar, Ital. J. Agron. 15, 57-62 (2020). DOI: 10.4081/ija.2020.1578, URL: https://www.researchgate.net/profile/Aissa_Abdelguerfi/publication/339897714 Adaptation_patterns_of_sixteen_alfalfa_Medicago_sativa_L_cultivars_across_contrasting_ environments_of_Algeria_and_implications_for_the_crop_improvement/links/ 5e95 cb54a6fdcca7891576̈be/Adaptation-patterns-of-sixteen-alfalfa-Medicago-sativa-Lcultivars-across-contrasting-environments-of-Algeria-and-implications-for-the-cropimprovement.pdf

10. J. Paderewski, H. G. Gauch, W. Mądry, T. Drzazga, P. C. Rodrigues, Crop Sci. 51, 969-980 (2011). DOI: 10.2135/cropsci2010.05.0278, URL: https://www.researchgate.net/profile/Tadeusz_Drzazga/publication/273673653_Yield_

Response_of_Winter_Wheat_to_Agro-

Ecological_Conditions_Using_ĀAdditive_Main_Effects_and_Multiplicative_Interaction_an d_Cluster_Analysis/links/

$5 \overline{6}$ f0f73608ae70bdd6c95e44/Yield-Response-of-Winter-Wheat-to-Agro-Ecological- 
Conditions-Using-Additive-Main-Effects-and-Multiplicative-Interaction-and-ClusterAnalysis.pdf

11. G. Singh, D. S. Kachwaya, R. Kumar, G. Vikas, L. Singh, Electron. J. Plant Breed.

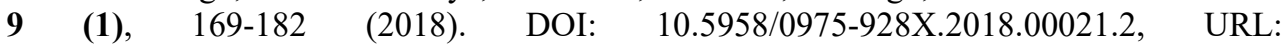
www.ejplantbreeding.org/index.php/EJPB/article/view/2298/1228

12. A. Gabriel, J. T. V. Resende, A. R. Zeist, L. V. Resende, N. C. V. Resende, A. G. Galvão, R. A. Zeist, R. B. de Lima Filho, J. V. W. Corrêa, C. K. Camargo, Genet. Mol. $\begin{array}{lllll}\text { Res. } & 17 & \text { (3), } 18041 \quad \text { (2018). DOI: } 10.4238 / \mathrm{gmr} 18041, \quad \text { URL: }\end{array}$ https://www.geneticsmr.com/sites/default/files/articles/year2018/vol17-3/pdf/gmr18041__phenotypic-stability-strawberry-cultivars.pdf

13. A. F. Costa, N. R. Leal, J. A. Ventura, L. S. A. Gonçalves, A. T. A. Júnior, H. Costa, Acta Sci., Agron. 37 (4), 435-440 (2015), DOI: 10.4025/actasciagron.v37i4.18251, URL: https://www.scielo.br/pdf/asagr/v37n4/1807-8621-asagr-37-04-00435.pdf

14. S. Holmes, W. Huber, Modern Statistics for Modern Biology (Cambridge University Press, NY, 2019)

15. B. G. Tabachnick, L. S. Fidell, Using Multivariate Statistics (Pearson PLC, London, 2013) 
Vadim Lapshin

8 (918) 343-88-37

lavai@list.ru

Federal State Budget Scientific Institution «North Caucasian Federal Scientific Center of Horticulture, Viticulture, Wine-making»

Research Associate of Laboratory of Variety study and Breeding of Garden crops

Valentina Yakovenko

8 (918) 661-91-54

yakovenko_valent@mail.ru

Federal State Budget Scientific Institution «North Caucasian Federal Scientific Center of Horticulture, Viticulture, Wine-making»

Senior Research Associate of Laboratory of Variety study and Breeding of Garden crops

Sergey Shcheglov

8 (961) 593-90-09

gold finch@mail.ru

Federal State Budgetary Educational Institution of Higher Education «Kuban State University»

Professor of the Genetics, microbiology, biochemistry Department 